\title{
Use of Social Resources by Elementary Schools in Taiwan and Resource Acquisition Strategies: Perspectives of Outstanding Principals
}

\author{
Tzung-Hsien Huang, Ya-Ching Yeh* \\ National University of Tainan, Taiwan \\ *yaching0315@yahoo.com
}

\begin{abstract}
Due to rapid social changes and shrinking family size, the management of Taiwan's elementary schools faces many severe challenges. The question of how to enhance school competitiveness has become an important issue that must be addressed by school principals. Looking from the resource-based view and the organizational ecology perspective, the acquisition of social resources by schools is an important mission for today's principals. Because of the great importance of social resources to school operation, and the great lack of research on the effective acquisition of social resources, this study seeks to employ systematic methods to examine how outstanding benchmark principals in Taiwan utilize social resources in order to acquire the resources their schools need for sustainable operation. Hence, the main purpose of this study is to explore how schools use social resources in order to maintain their competitiveness, and their strategies for acquiring social resources, from the perspectives of outstanding principals. The results of this study reveal (1) eight findings concerning how public elementary school principals' perspectives on the use of social resources, such as active interaction with the community, establishment of networks of diverse relationships, obtaining recognition of superior teaching, and school marketing; and (2) ten findings concerning elementary school principals' strategies for acquiring social resources, such as maintenance of personal relationships, establishment of distinctive school features and enhancement of teaching performance, and skillful use of communication to acquire social resources. These important research results reveal a wide range of social resource utilization and acquisition strategies, and suggest the necessity and value of the implicit knowledge and wisdom that principals bring to bear in the workplace.
\end{abstract}

Keywords: Social resources; Resource acquisition; Elementary school; Principal

\section{Introduction}

Due to rapid social changes and shrinking family size, the management of Taiwan's elementary schools faces many severe challenges. How to enhance school competitiveness has become an important issue for school principals. According to Jones and George (2008), one of the main challenges faced by contemporary managers is the establishment of a competitive advantage. It implies the use of resources 
to create a competitive advantage that will further enhance the organization's effectiveness and performance in providing internal and external customers with needed products and services. Hafeez et al. (2002) suggest that the most important task for a corporate organization wishing to obtain a competitive advantage is to gather strategic resources. It can use to uncover its unique key capabilities, establish its core competitiveness, and thereby acquire or maintain a competitive advantage. Scholars advocating a "resource-based view" (RBV), such as Barney (1991), Grant (1991), and Wernerfelt (1984), believe that the controlling development of an organization's unique inherent, internal strategic resources, including assets, resources, and capabilities, will allow it to maintain or acquire a sustainable competitive advantage. These perspectives indicate that the acquisition of resources is a key factor in obtaining a competitive advantage. After investigating and debating reforms to elementary and middle school education in 1996, the government of Taiwan reached the following conclusions: (1) a school-based operating concept should be emphasized, and (2) schools should be given more autonomy and professional leeway. As a consequence, in order to fully realize educational reforms at the elementary school level, leaders (i.e., principals) would bear responsibility for actively acquiring and utilizing relevant resources, facilitating school administration.

From the point of view of organizational ecology, schools must interact and engage in interchange with the external environment in order to obtain needed resources (Daft, 2008). According to Geller and Salamon (2010), nonprofit organizations (NPOs) such as schools must actively seek social resources, strictly control their expenditures, and employ corporate-style operating strategies in response to fiscal tightening. Addressing the challenges of a changing environment, Wu (2005) suggested that school principals discard conventional closed administrative approaches, reach out beyond the campus, and merge with the community in order to obtain various social resources, which can be used to create distinctive and outstanding administrative features. These research conclusions indicate that obtaining social resources are one of the most important tasks for school principals. While Taiwan's public schools chiefly depend on the government for their funding resources, under the civil service budget system, funding for schools often cannot completely meet the needs of their autonomous use of space and flexibility, and the economic downturn and the government's tightening of educational funding has starved public schools of the funds needed for their development (Chen, 2002). Responding to rapid changes in the internal an extra environment, and facing restrictions on the government's funding resources, school leaders must actively seek social resources from sources other than the government. These include tangible and intangible resources such as manpower, material resources, funding, and culture (Bagin and Gallagher, 2001; Cheng, 2005; Fox and Wilson, 2008; Jimenez-Castellanos, 2010; Kilpatrick et al., 2011; Mulford, 2011; Pilo et al., 2011; Wiepking and Maas, 2009; Wu, 2006). The application of new thinking and methods to the acquisition and use of social resources (Mark, 2011), can help schools to overcome various difficulties, develop distinctive features, and enhance their competitiveness. 
In spite of the importance of social resources to school administration, the literature (Lin, 2002; Fan, 2008; Chang, 2008; Tang, 2001; Huang, 2005; Hsieh, 2007) provide only cursory descriptions of community resources and resource utilization, and there is a great lack of information on the issue of how to effectively obtain social resources. In order to understand elementary school principals' secrets and strategies for obtaining social resources, this study uses systematic research methods to gather the views of a number of outstanding benchmark principals concerning the use of social resources, and how they can obtain social resources to facilitate school operation. In addition, this study expects that the implicit knowledge and wisdom used by elementary school principals to uncover useful social resources and thereby make up for their schools' lack of resources will guide schools' efforts to acquire social resources. Based on the foregoing considerations, the purpose of this study is to rely on the viewpoints of benchmark elementary school principals to investigate schools' strategies for obtaining social resources and how they use social resources to obtain a competitive advantage. Then, the related literature is reviewed. The next section presents research methods. Consequently, an empirical study is surveyed. Finally, concluding remarks are made in the last section.

\section{Literature Review}

Concept of social resources: Grant (2002) suggests that resources are the outputs of production processes, and constitute the most basic units of analysis. In accordance with RBV, an organization's future development direction and the competitiveness of its individual business units hinge on the core competitiveness or core resources of the organization as a whole. Resources are the key to an organization's competitive advantage, and emphasis should be placed on the identification, cultivation, development, and protection of an organization's unique core resources. Depending on the substance of their research, different scholars hold differing views concerning the concept of resources; the resource concept is by no means fixed and unchanging. For instance, certain resources will change in a hypercompetitive environment (D'Aveni, 1994). The competence-based perspectives (CBP) (Prahalad and Hamel, 1990) emphasizes that the capabilities of resources may increase due to leverage effects (Grant, 2002). As a consequence, the possibility exists that resources may generate new resources or replaces old resources via dynamic resource creation, accumulation, leverage, acquisition, exchange, and use (Fong, 2000). The acquisition of resources refers to the procurement of resources from a source outside the organization. When an organization cannot achieve some future strategic objective with its existing resources, it must obtain resources externally. It has been mentioned that while Taiwan's elementary schools chiefly depend on funding resources provided by the government, these funding resources often cannot meet schools' development needs. Because of this, it may be necessary for school principals to seek social resources from sources outside of the government to facilitate school development.

Halley (1992) proposes that services provided through social legislation or voluntary citizen action can be considered social resources. For instance, the services provided by public, private, or volunteer 
organizations such as hospitals, adoption organizations, schools, daycare centers, libraries, welfare centers, social security programs, and family service organization are all social resources. Furthermore, some other scholars (Jimenez-Castellanos, 2010; Mulford, 2011; Rhodes, 2001; Tuffy, 2011; Wu, 2006) have explored the implications of social resources. Summarizing the views of a number of scholars, this study defines social resources as: tangible and intangible resources, including funds, manpower, material resources, or culture/history that can be used by a school to increase performance or efficiency. The types of resources are described as follows:

- Funding resources (Garner, 2004; Jimenez-Castellanos, 2010; Thompson and Wood, 2001; Wiepking and Maas, 2009; $\mathrm{Wu}, 2006)$. It includes all kinds of financial donations, subsidies, scholarships, financial contributions, and fund monies.

- Manpower resources (Bagin and Gallagher, 2001; Fox and Wilson, 2008; Jimenez-Castellanos, 2010; Kilpatrick et al., 2011; Mulford, 2011; Wu, 2006). It includes all persons able to assist school education, including professional personnel, local leaders, volunteers, personnel in various occupations, and residents.

- Material resources (Jimenez-Castellanos, 2010; Mckinney, 1996; Wiepking and Maas, 2009; Wu, 2006). It includes natural resources, biological resources, and organizational facilities. For instance, material resources may include land, water sources, seashores, mountain areas, and all types of minerals, national scenic areas, social organizations, and their facilities that can be used in a school's educational activities.

- Cultural and historical resources (Pilo et al., 2011; Tuffy, 2011; Wu, 2006). All types of cultural works, artifacts, buildings, or historical sites in society possessing cultural value, cultural content, or historical significance that can be used in school education.

Exploring perspectives on the use of social resources: As society changes, many new perspectives on the utilization of social resources have been proposed. For instance, Araujo (2011) suggests that the integration of financial, information, assistance, and teaching resources can help students to achieve optimal in-school learning. Kappan (2006) argued that while educational resources are limited, social resources boundless, and asserted that when a majority of parents express a desire for high quality school education, schools' existing resources may not be able to satisfy parents' educational quality expectations. Schools that wish to escape the effect of educational resource cutbacks, while satisfying parents' requirement for better educational quality, must learn to obtain educational resources facilitating their development from society at large. Chesbrough $(2003 ; 2006)$ and Enkel et al. $(2009)$ proposed that organizations overturn resource utilization boundaries and use social resources through open innovation. According to these scholars, organizations should not be limited to their internal resources, but must rely on innovation to make the best use of external resources in order to respond to the fast-changing market and obtain a competitive advantage. The authors believe that this viewpoint is worthy of reference by school managers. Furthermore, Daniel and Wilson (2003) believe that organizations cannot depend solely on existing resources and methods when facing new competitive environments, but must be able to 
constantly recombine resources, obtain new resources, and make best use of idle resources. According to Chang and Chou (2011), organizations must make the best use of their corporate resources to promote learning performance. Wisner et al. (2010) suggest that schools can cooperate with social workers in order to enhance teenagers' attitudes and self-management through activities.

Some scholars (DeStefano et al., 2000; Epstein, 2009; Gestwicki, 2007; Jones, 2011; Marcia and Sharon, 2009; Sergiovanni, 1994) have proposed a closer linkage between schools and the community, and suggest that the use of resource analysis, establishment of partnerships, and sharing and effective utilization of community resources can boost schools' operating performance. This view supposes that community resources are a type of social resource, community resources are usable resources, and that there is a need to see the community as a partner and source of social resources in the "sphere of living." In addition, utilization of social resources should not be limited by unitary thinking; instead, schools should use social resources through an integrated perspective (Huang and Cheng, 2008) in line with multifaceted considerations. Schools and the community should be integrated parts of a larger organizational ecology, and should mediate social forces influencing students' learning. With regard to social resources, school leaders should adopt new outlooks, diversified thinking, and an integrated utilization perspective, or should apply the concept of "resource substitution" by seeking out new methods to achieve the goal of effective resource utilization (Kappan, 2006; Wiepking and Maas, 2009).

Acquiring social resources: Various methods of obtaining social resources have been proposed, including the time window theory (Conrad, 1974), necklace theory (Conrad, 1974), pyramid theory (Greenfield, 1997), transaction analysis theory (Conrad, 1974), and evolution theory (Worth, 1993), and these theories can provide guidance to schools seeking to obtain social resources. First, we can find that the acquisition of social resources by school organizations should emphasize linkage with social needs and the values and beliefs of resource donors, and should also ensure that resource donors also benefit from resource-gathering activities. Secondly, apart from routinely maintaining good relationships with resource donors, schools should apply time window theory by enhancing the willingness of resource donors to donate their resources through the holding of promotional events or taking advantage of key moments. Thirdly, schools should put effort into creating value associated with resource-recruiting activities, which will induce a sympathetic response and continued donation on the part of resource donors. Finally, schools should emphasize the establishment of long-term relationships with resource donors and ensuring benefits to donors, which will reinforce commitment to the school and emotional linkage, promoting continued contribution of resources. Furthermore, some scholars have proposed specific methods for obtaining social resources. For instance, Chang and Chou (2011) suggest the systematic acquisition of corporate resources. Karen et al. (2003) proposed the use of information technology to evaluate differences between areas, locate resources, and assess their availability, enabling the production social resource utilization maps helping schools to locate and obtain social resources. According to Kilpatrick et al. (2011), many professional personnel exist in the community, and schools 
can utilize surveys to understand and find correct methods of interaction enabling the most effective use of these resources with professional backgrounds. Pilo et al. (2011) pointed out that schools can take advantage of science center social in course design. Tuffy (2011) proposed the four elements of detailed prior planning, interactive learning, mission-oriented activity design, and extended learning, and schools may therefore take advantage of historical and cultural resources to promote student learning.

Synthesis: This study summarized the following chief feasible methods that can be used by schools to obtain social resources from the foregoing literature:

- Establishment of social resource maps: Collection and compilation of possible sources and social resources and creation of social resource maps in order to gain an overall picture of tangible and intangible resources available for school use, including manpower, material resources, funding, and cultural/historical resources.

- Creation of effective interpersonal networks: School organizations should create networks of internal and external relationships and establish excellent linkage; in particular, schools should establish stable, effective, long-term interpersonal relationships with key resource-raising targets.

- Active use of various resource acquisition strategies: For example, schools should emphasize connection with social needs and the values and beliefs of resource donors, and should also ensure that resource donors also benefit from resource-gathering activities. Schools should also apply the time window theory by holding promotional events or taking advantage of key moments, emphasize the creation of value from resources-raising activities, foster a sympathetic response in resource donors, establish long-term relationships with resource donors and encourage donor loyalty, and establish strategic alliances by extending the classroom into the community or society at large.

- Establishment of distinctive school features and enhancement of school performance: School organizations wishing to obtain social resources must cultivate a good school reputation, develop distinctive features, boost their performance, and highlight teaching results; this will encourage recognition among individuals inside and outside the school, attracting greater amounts of resources.

- Actively competing for and communicating ties: School organizations should actively communicate their ties beyond the campus and vigorously compete for support. Schools should also emphasize internal communication. Because innovations in the use of social resources will inevitably impact existing operating models, it is important for schools to establish excellent channels of communication, continuously communicate and publicize themselves, and rely on interpersonal relationships and group participation to achieve a consensus concerning the acquisition and utilization of social resources among colleagues.

\section{Methodology}

Because research methods (Herzog, 1996) are used to achieve the goals of a research project, the chosen research methods must be appropriately connected and applied on the basis of the research goals. This 
study relied on interviews (Herzog, 1996) to gather empirical data. The goal of the interviews was to gain an understanding of the strategic secrets used by the respondent principles to acquire social resources.

Interview method: The interviews involved direct verbal interaction between the interviewers and respondents, and this method consequently had some advantages and disadvantages. Advantages included the ability to acquire a complete body of data, gain a good understanding of core issues, express clear goals, assess the reliability of answers, and control the order of questions. This method also has certain drawbacks, however, such as interviewers' subjective views and bias, need to commit relatively large amounts of time and money, lack of standard question wording, and respondents' frequent unwillingness to answer certain sensitive questions, all of which lowered the reliability and validity of the interviews. Interviews are inherently a highly subjective method. Great efforts must be made to employ control and guard measures if it is wished to obtain reasonable, objective, and unbiased data. To obtain the research data actually needed, research interviews must proceed in accordance with detailed research objectives, so as to ensure the appropriate of the handbook and interview procedures. The interviews in this study were carefully designed and structured. The judgments of the interviewed experts greatly facilitated determination of questions eliciting important information and enabling attainment of the research goals.

Data collection and procedure: This study interviewed elementary school principals known to be good performers with regard to the "acquisition and utilization of social resources." The study interviewed 30 principals who had been recommended by their fellow principals and officials at the education competent authority. The interview question framework consisted of two chief parts: One part asked: "What new perspectives or views toward the use of social resources do you hold that contrast with past or traditional views?" The other part asked: "How do you acquire social resources needed for the operation of your school? Please explain your secrets." The data analysis in this study sought to ensure reliability. Four methods were employed to ensure the reliability of the interview data: (1) each interview manuscript was rechecked after transcription. (2) The checked transcriptions were sent to the respondents for confirmation. (3) The transcribed data was summarized in accordance with the research questions and listed on the basis of content attributes, and then rechecked; the content of certain items was adjusted when further integration was possible, and the names revised. (4) Experts and scholars were asked to inspect the listed data that had been sorted; adjustments were made on the basis of the consensus reached in discussion of items the experts and scholars felt could be reviewed. The interviews and data transcription and analysis in this study were chiefly performed by researchers and doctoral student assistants who had received prior training. The interview recordings were first individually transcribed, the responses to each question were then compiled, and categories and names assigned on the basis of content attributes. After sorting and analysis of the interview data, important new perspectives and strategies were extracted from the data via encoding. 


\section{Results and Discussion}

In this section, the research findings of new perspectives on social resource utilization and strategies for the acquisition of social resources are described as follows.

New perspectives on social resource utilization: This study obtained eight findings concerning new perspectives on social research utilization from analysis of the qualitative interview data; these findings consisted of:

- Active interaction with the community and appraisal of the state of community resources, facilitating acquisition of resources: The elementary school principals believed: "(1) Mutual recognition can enable community identification with the school and the principal. (2) When a principal has lived in the community for over 20 years, he will understand community resource utilization strategies. (3) School marketing and interaction with the community can enable community resources to be obtained. (4) Active involvement in the community, frequent contact, and explanation of the school's needs. (5) Target resources needed by the school on the basis of the community's characteristics, and create awareness that the school belongs to the community and coexists with it." These responses imply that schools must cooperate with the community if they wish to facilitate the acquisition of social resources.

- Pay attention to the establishment of networks of diverse relationships, which will facilitate the acquisition of social resources: The elementary school principals believed: "(1) Make friends everywhere and establish multilevel social resource utilization networks; work your way up to a larger scope of interaction, and construct an all-encompassing resource network. (2) Rely on relationships with peers to invite members of other schools' parents' associations and advisory groups to join the school's advisory group. (3) Interact with alumni associations and retired teacher, and establish ties with various private groups in the community, in order to obtain assistance in acquiring social resources and funding. (4) Make good use of existing manpower and volunteers, who should be organized and structured so as to make the school's social network more complete and effective." These findings suggest that the establishment of networks incorporating diverse relationships facilitates the acquisition of social resources.

- Use of scholastic performance and school marketing to obtain recognition: The elementary school principals believed: "(1) Resources will pour in if you can ensure that everyone is aware of your scholastic results. Use of school marketing can ensure that the outside world identifies with the school and is willing to provide resources to support the school's growth. (2) Make sure that everyone inside and outside the school can see and talk about the effectiveness of the school's resource utilization, which will ensure the greater community identifies with the school. (3) Schools should think about how they can make breakthroughs, transform themselves, innovate, and maintain their growth momentum. These ideas will influence teachers, and because schools are competing in the market, schools that offer very good service will attract the best teachers. (4) 
Parents and alumni will be willing to support a school with resources and funding when the school has a well-run alumni association or has been praised by outstanding alumni." These responses indicate that scholastic performance and school marketing can be used to obtain external recognition, facilitating the school's acquisition of social resources.

- Transcend boundaries in seeking resources, and use social resources in an innovative manner: The elementary school principals believed: "(1) Go beyond the educational sphere and obtain support in the form of human and material resources in the community. The resources that can be found in society at large include tangible materials, good ideas, professional manpower, organizational resources, intellectual property, libraries, and the media. (2) Rely on cooperation with nonprofit and government organizations, universities, and colleges to acquire supporting social resources. (3) Use public relations to establish an effective network of interpersonal relationships, and strive to obtain social resources from the government bureau of education after considering the relationship between the government and the social context." This suggests that crossing boundaries in seeking resources will facilitate the discovery and utilization of social resources.

- Remain watchful for opportunities to acquire resources, which should be used in conjunction with the school's situation and local development: The elementary school principals believed: "(1) Acquiring resources is an uncertain process, and taking advantage of appropriate opportunities is one of the keys to acquiring social resources. (2) A school's culture and education should be in harmony with the community's culture and education, and the use of social resources should reflect local people and conditions. (3) Schools should conduct market surveys concerning their distinctive features, and should differentiate themselves. Use the community's social resources in conjunction with the community culture and local features." These responses indicate that opportunities to acquire social resources should be seized, and the school's situation and local developments may facilitate the use of social resources.

- Emphasize the integration of resources: Some of the elementary school principals believed: "(1) Promotion of integrated resource utilization will help supplement the school's facilities and equipment. (2) In order to preserve the school's cultural and historical resources, improve the campus landscape, and eliminate dead corners, the school should seek assistance from university art professors and students, and secure funding resources, for the sake of improving school's cultural features and landscape." In addition, some of the principals also believed: (1) "Schools can integrate their resources to offer some special classes, such as parenting education and adult education, which will enhance their educational function, and also help them establish relationships with other schools. (2) Schools can ask experts and scholars to help train volunteer groups, facilitating utilization of school or community manpower. (3) Schools can hold various external community activities, and thereby obtain external financial resource inputs." These responses tell us that emphasis on integration of resources can facilitate the acquisition of social resources. 
- Use of acquired social resources to develop the school's distinctive features: The elementary school principals believed: "Acquire various resources that can be used to give the school distinctive features. For instance, a school can hold activities connected with the sea or promote a superior cultural and artistic environment. Rely on the school's various special features to highlight its need for social resources." This indicates that school operation should be in harmony with the local community or local customs, which will facilitate the acquisition of social resources.

- Establish a school vision, and use resources appropriately: The elementary school principals believed: "(1) Social resources should not be used haphazardly. After analyzing the school's state of development and needs, establish a school vision and goals, and use resources appropriately so as to facilitate attainment of the vision and goals. (2) After establishing a development vision, manpower, material resources, and financial resources, etc. can be used to attain the school's operating goals." These responses suggest that setting a development vision and employing social resources in conjunction with that vision will benefit the school's operation.

- Strategies for the acquisition of social resources: This study obtained ten findings concerning strategies for acquisition of social resources from analysis of the qualitative interview data; these findings consisted of:

- Maintenance of personal relationships, use of personal connections to acquire resources: The elementary school principals believed that schools can uncover available internal and external resources by establishing relationships and personal connections through the following channels: Introduction by parents' associations members, recommendations from school teachers, reliance on interdisciplinary alliances between schools at different levels to contact relevant authorities, maintenance of good relationships with government units, referrals from friendly individuals, and acquisition of resources via parents' contact with legislators.

- Establishment of distinctive school features and enhancement of teaching performance, enabling the acquisition of resources and recognition: The elementary school principals believed that schools must emphasize their performance and distinguishing features; parents and other members of society will be willing to provide resources to help a school's needs when they see the school's hard work and results. For example, schools can first promote knowledge of the community, and can incorporate community history, culture, and natural and ecological features in their instruction. By combining teaching with the community environment, a school can obtain the support and resources of local people.

- Use a diversified strategy consisting of written plans, events, the media, and personal presentation of accounts and results: The elementary school principals believed that skillful methods should be used to acquire funds and resources. For instance, proposals can be written to government and private funding and resources, schools can rely on large-scale events to establish contact with relevant individuals or organizations, reports in the media can help a school to obtain resources, strategic contacts can enable the school to acquire needed and usable 
educational resources, visits can be made to social resources providers to request resources needed by the school, and well-written budgets can be used to show supporting organizations how their money will be spent. In addition, principals can also personally thank donors and show them proof of the school's scholastic performance, securing their continued support and funding.

- Skillful use of communication and contact: The elementary school principals believed that communication and contact can be used to find social resources. This may consist of frequent interaction with the community, making contact with individuals and organizations through activities, active presentation of information and plans as a form of public relations, showing concern for others' well-being, making telephone enquiries, community-building projects, establishment of mutual trust and recognition, and the invitation of relevant experts and teachers to participate in community activities.

- Reliance on the principle of mutual benefit to facilitate acquisition of resources: The elementary school principals believed that the principle of mutual benefit can be used to locate social resources. This may take the form of helping the government or the responsible authorities to hold activities in order to obtain attention and funding resources, sharing of facilities or manpower with the community or other schools, and other methods of obtaining resources needed by the school via mutually beneficial approaches.

- Accessing and establishing online resource databases facilitating acquisition of resources:

The elementary school principals believed that online resource databases can be used to find social resources, and can be compiled and maintained by locating key individuals in the community, regularly collecting and posting social resources information online for use by students and teachers, asking parents and teachers to provide lists of recommended persons and organizations that can provided resources, and sorting and comparing information to help secure needed resources.

- Actively hosting or participating in external activities in order to obtain various resources: The elementary school principals believed that actively securing hosting rights to or participating in external activities can help schools find social resources. For instance, schools can gain the right to host activities by contacting appropriate organizations or offices, actively contact social resource providers and ask them to provide resources needed by the school, independently establish two-way relationships meeting the school's development needs, participating in department store celebration activities, and conducting performance or lecture activities while seeking resources.

- Employment of systematic and trustworthy resource utilization methods, building trust and encouraging the provision of resources: The elementary school principals believed that a key secret to obtaining social resources is to establish systematic or trust-inspiring resource use methods, which will set providers' minds at ease and encourage them to provide resources to the school. However, although the systematic utilization of resources can facilitate the acquisition of resources, care should be taken that this approach does not become an extension of the 
principal's personal relationships. Schools that can maintain the transparency of their resources use will elicit trust from resources providers.

- Emphasis on media marketing: The elementary school principals believed that schools can use media marketing and school results reports to create awareness of their hard work and foster a positive impression of the school among the public, which will facilitate the gathering of resources. In addition, schools' activities should be innovative, which will attract reporters and ensure coverage.

- Use of the Internet to search for and solicit resources: The elementary school principals believed that schools can use the Internet to search for resource providers (such as the websites of the Chinese Fund for Children and Families, World Vision Taiwan, Red Cross, public offices, and universities), which will facilitate the acquisition of information and useful resources. Furthermore, schools can also use the Internet to make announcements and recruit volunteers to participate in school activities.

\section{Conclusion and Recommendations}

Conclusion: The management of Taiwan's elementary schools faces many severe challenges, and how to enhance school competitiveness has become an important issue for school principals. Based on the RBV and organizational ecology perspectives, the acquisition of social resources by schools is an important mission for today's principals. Hence, this study seeks to employ systematic methods to examine how outstanding benchmark principals in Taiwan utilize social resources in order to acquire the resources their schools need for sustainable operation. The main purpose of this study is to explore how schools use social resources to maintain their competitiveness, and their strategies for acquiring social resources, from the perspectives of outstanding principals in Taiwan. Then, the related literature - including the concept of social resources, the exploring perspectives on the use of social resources, and the methods of acquiring social resources - are reviewed. Consequently, an empirical study via the interviews was to gather empirical data. The goal of the interviews was to gain an understanding of the strategic secrets used by the respondent principles to acquire social resources. Finally, the findings of this study obtained:

- Eight findings concerning new perspectives on social research utilization: Regarding the social research utilization, the foregoing research findings indicate that the principals' viewpoints are active and enlightened, which is consistent with the theoretical conclusions and empirical results in some literature (Chang and Chou, 2011; Chesbrough, 2006; Daniel and Wilson, 2003; Jones, 2011; Kappan, 2006), and shows that they hold up-to-date attitudes toward the utilization of social resources. The respondent principals made little direct mention of the concepts from the literature of "regarding the community as the sphere of living," "schools and the community should be integrated parts of a larger organizational ecology, and should mediate social forces influencing students' learning," and "resource substitution," but these perspectives can be further promoted and applied in the future.

- Ten findings concerning strategies for acquisition of social resources: Regarding the strategies 
for acquisition of social resources, the foregoing research results reveal that the respondent principals used the strategies described in the literature to obtain social resources, namely maintenance of personal relationships, skillful use of communication and contact, establishment of distinctive school features and enhancement of school performance, actively securing resources, and using online searches for resources (Karen et al., 2003; Pilo et al., 2001; Tuffy, 2011). In addition, the principals also demonstrated their ability to accommodate changes in the social environment and develop their own methods for obtaining resources. For instance, principals wrote proposals, relied on the principle of mutual benefit, made online announcements, held or participated in off-campus activities, and established systematic and trustworthy resource utilization methods. The principals' accounts of their social resource acquisition secrets, such as "because parents are very worried that the school will spend money wastefully, transparency is very important," "people will trust the school only if we let supporting organizations know what we are spending money on and show that we are using it wisely," "I thank donors individually and show them a record of our scholastic performance," "I make contact with relevant individuals or organizations via the school's major events," and "we use the media to report information and obtain resources for the school," are vivid and worthy of reference. These valuable, concrete research results reveal a wide range of social resource acquisition strategies, and show the necessity and value of the implicit knowledge and wisdom that principals bring to bear in the workplace.

Recommendations: Based on the foregoing research results, this study recommends:

- The new social resource utilization perspectives of the respondent principals were active and consistent with academic theory. In the future, more study and extension effort can be devoted to relevant perspectives, such as "regarding the community as the sphere of living," "schools and the community should be integrated parts of a larger organizational ecology, and should mediate social forces influencing students' learning," and "resource substitution and innovative use."

- The methods used by the respondent principals to obtain social resources and their example activities are clever and diverse. They are not only worthy of reference, but also verify and highlight the necessity and value of the implicit knowledge and wisdom that principals bring to bear in the workplace.

- Principals can obtain intellectual stimulation from the results of this study and be inspired to develop appropriate school service action plans, and actively secure and apply various social resources meeting scholastic needs and enhancing instructional performance.

- Scholars and principals can conduct further research on social resource utilization perspectives and activity secrets in the future, which will help broaden perspectives and yield more of principals' implicit workplace knowledge and active intelligence.

- Continuing efforts can be made to deepen and actually apply such perspectives as "regarding the community as the sphere of living," "schools and the community should be integrated parts of a larger organizational ecology, and should mediate social forces influencing students' learning," and 
"resource substitution and innovative use."

- Continued study and construction of a comprehensive social resource utilization conceptual system and action framework, facilitating use by principals.

\section{References}

Araujo, B. (2011). The college assistance migrant program: A valuable resource for migrant farm worker students. Journal of Hispanic Higher Education, 10(3), 252-265.

Bagin, D. \& Gallagher, D. R. (2001). School community relations. Boston: Allyn \& Bacon.

Barney, J. B. (1991). Firm resources and sustained competitive advantage. Journal of Management, 17(1), 99-120.

Chang, D. F. (2008). Educational administration: Theories and innovations. Taipei: A books company.

Chang, H. H. \& Chou, H. W. (2011). Drivers and effects of enterprise resource planning post-implementation learning. Behavior \& Information Technology, 30(2), 251-259.

Chen, L. J. (2002). The impact of the systematization of local grants policy on school finance. Educational Review, 19, 91-119.

Cheng, H. G. (2005). The connections between community resource and school education. Inservice Education Bulletin, 22(1), 88-94.

Chesbrough, H. (2003). Open platform innovation: Creating value from internal and external innovation. Intel Technology Journal, 7(3), 5-9.

Chesbrough, H. (2006). Open business models: How to thrive in the new innovation landscape. New York: Harvard Business Pres.

Conrad, D. L. (1974). Techniques of fundraising. Secaucus, NJ: Lyle Student Inc.

Daft, R. (2008). Organization theory and design. New York: West Publishing.

Daniel, E. D. \& Wilson, H. N. (2003). The role of dynamic capabilities in e-business transformation. European Journal of Information Systems, 12(4), 282-296.

D’Aveni, R. A. (1994). Hyper competition. New York: The Free Press.

DeStefano, J. R., Van Hook, S. \& Draht, S. (2000). The future connection. American School \& University, 72(5), 24-25.

Enkel, E., Gassmann, O. \& Chesbrough, H. (2009). Open R\&D and open innovation: Exploring the phenomenon. Business \& Management, 39(4), 311-316.

Epstein, J. L. (2009). School, family and community partnerships. Thousand Oaks: Corwin Press.

Fan, C. W. (2008). School management: Concept, theory, and practice ( $2^{\text {nd }}$ edition). Kaohsiung: Liwen Publisher.

Fong, C. M. (2000). Business competitive advantage. Taiwan: Chien-Cheng Publishing.

Fox, A. \& Wilson, E. (2008). Viewing recently qualified teachers and their networks as a resource for a school. Teacher Development, 12, 97-100.

Garner, C. W. (2004). Education finance for school leaders: Strategic planning and administration. Upper 
Saddle River, N.J.: Pearson Prentice Hall.

Geller, S. L. \& Salamon, L. M. (2010). Museums and other nonprofits in the current recession: A story of resilience, innovation, and survival. Journal of Museum Education, 35(1), 129-140.

Gestwicki, C. (2007). Home, school and community relations. Clifton Park: Thomson Delmar.

Grant, R. M. (1991). The resource-based theory of competitive advantage: implications for strategy formulation. California Management Review, 33(3), 114-135.

Grant, R. M. (2002). Contemporary strategy analysis: Concepts, techniques, applications (4th edition). UK: Blackwell Publishers Inc.

Greenfield, J. M. (1997). Fund-raising: Evaluation and management the fund development process. New York: John Wiley \& Sons.

Hafeez, K., Zhang, Y. B. \& Malak, N. (2002). Core competence for sustainable competitive advantage: A structured methodology for identifying core competence. IEEE Transactions on Engineering Management, 49(1), 28-35.

Halley, A. A. (1992). Delivering human services (3 $3^{\text {rd }}$ edition). New York: Longman.

Herzog, T. R. (1996). Research methods and data analysis in the social sciences. New York: Pearson.

Hsieh, C. Y. (2007). A study on the use of community resources and the effectiveness in elementary schools of Taipei County. Master thesis, National Taiwan Normal University.

Huang, S. H. (2005). A practice study on the use of parents and social resources. Teachers Bulletin, 134, 60-63.

Huang, T. S. \& Cheng, M. Z. (2008). Innovative leadership of the winner of outstanding leadership award and its implications for school. Contemporary Educational Research Quarterly, 16(4), 109-153.

Jimenez-Castellanos, O. (2010). Relationship between educational resources and school achievement: A mixed method intra-district analysis. Urban Review, 42(4), 351-371.

Jones, D. (2011). Make your PTA an essential resource to your community. Our Children: The National PTA Magazine, 36(4), 9-10.

Jones, G. R. \& George, J. M. (2008). Essentials of contemporary management (3 ${ }^{\text {rd }}$ edition). New York: McGraw-Hill.

Kappan, P. D. (2006). Why are schools always begging for money? Elementary and Secondary Schools, 88(1), 70-75.

Karen, W., Daniel, E. \& Adrian, F. (2003). The quality of urban environments: Mapping variation in access to community resources. Urban Studies, 40(1), 161-77.

Kilpatrick, S., Johns, S., Vitartas, P. \& Homisan, M. (2011). Mobile skilled workers: Making the most of an untapped rural community resource. Journal of Rural Studies, 27(2), 181-190.

Lin, M. D. (2002). The relationship between school and community. Taipei: Wu-Nan.

Mckinney, J. R. (1996). Legal and ethical aspects of public relations. In T.J. Kowalski (ed.), Public relations in educational organization (92-116). Englewood Cliff, NJ: Merrill.

Marcia, M. \& Sharon, B. W. (2009). Case study of leadership practice and school community interrelationships in high-performing, high-poverty, rural California high schools. Journal of 
Research in Rural Education, 24(1), 1-18.

Mark, P. (2011). Schools, teachers, and curriculum change: A balancing act? Journal of Educational Change, 12(1), 1-23.

Mulford, B. (2011). Teacher and school leader quality and sustainability. Resource Sheet No. 5. Retrieved from ERIC database. (ED516157)

Pilo, M., Mantero, A. \& Marasco, A. (2011). Science centers: A resource for school and community. US-China Education Review, 8(1), 80-88.

Prahalad, C. K. \& Hamel, G. (1990). The core competence of the corporation. Harvard Business Review, 68(3), 79-91.

Rhodes, C. (2001). Resource management for school: A handbook of staff development activities. London: David Fulton Publishers.

Sergiovanni, T. J. (1994). Building community in schools. San Francisco: Jossey-Bass.

Tang, Y. (2001). School management and strategies. Taipei: Wu-Nan.

Thompson, D. C. \& Wood, R. C. (2001). Money and schools (2nd edition). New York: Eye on Education Inc.

Tuffy, J. (2011). The learning trip: Using the museum field trip experience as a teaching resource to enhance curriculum and student engagement. Retrieved from ERIC database. (ED517713)

Wernerflet, B. (1984). A resource-based view of the firm. Strategic Management Journal, 5(2), 171-180.

Wiepking, P. \& Maas, I. (2009). Resources that make you generous: Effects of social and human resources on charitable giving. Social Force, 87(4), 73-95.

Wisner, B., Jones, B. \& Gwin, D. (2010). School-based meditation practices for adolescents: A resource for strengthening self regulation, emotional coping, and self-esteem. Children \& Schools, 32(3), 150-159.

Worth, M. J. (Ed.) (1993). Educational fund raising: Principles and practice. Phoenix, AZ: Oryx Press.

Wu, C. S. (2006). Introduction to education (2nd edition). Taipei: Wu-Nan.

Wu, W. H. (2005). Community resource and excellent school management. Journal of Education Research, 135, 26-37. 